\title{
De afins e afetos: conjugalidades, parentalidades e novas identidades
}

\section{Conjugalidades, parentalidades e identidades lésbicas, gays e travestis.}

GROSSI, Miriam; UZIEL, Anna Paula; Mello, Luiz (Orgs.).

Rio de Janeiro: Garamond, 2007. 430 p.

Apresentado por Miriam Pillar Grossi (UFSC), Anna Paula Uziel (CLAM, IMS-UERJ) e Luiz Mello (UFG), Conjugalidades, parentalidades e identidades lésbicas, gays e travestis ${ }^{1}$ é uma coletânea de artigos de várias/os pesquisadoras/ os brasileiras/os e estrangeiras/os que forma uma rede ampla e multidisciplinar envolvida com as temáticas das afetividades ${ }^{2}$ e parentalidades $L G B T^{3}$

O livro é um trabalho de fôlego. Cobre um grande campo de discussões em torno de aspectos fundamentais das relações sociais de gays, lésbicas e travestis. Das relações homoafetivas, passando por parentalidades travestis, gays e lésbicas, por políticas e direitos LGBT e pelas representações da mídia sobre homossexualidade, os artigos contemplam diversos campos de saber como a psicologia, a antropologia, a sociologia, o direito e a comunicação e contrapõem-se aos saberes institucionalizados acerca das sexualidades, 
especialmente ao discurso médico, o que é exatamente uma grande contribuição. Antes desse livro, parece-me que o que se tinha era uma quantidade significativa de textos dispersos por diversas áreas. O que surge agora é uma mostra de que o campo das sexualidades, especificamente no que tange às conjugalidades e parentalidades gays, lésbicas e travestis, constitui, por si só, um complexo campo de estudo que vem se consolidando. Nesse livro, o diálogo "interno" envolvendo pesquisadoras/os e pesquisas com origens nacionais bastante distintas (Argentina, Chile, Brasil, Portugal, Espanha e França) produzido pela rede Parceria Civil, Conjugalidade e Homoparentalidade ${ }^{4}$ é trazido ao público especializado e figura como uma contribuição significativa tanto no campo teórico dos estudos queer quanto nas lutas do movimento LGBT.

O livro se divide em três partes "Conjugalidades", "Parentalidades" e "Identidades Lésbicas" - que revelam a multiplicidade e a complexidade das relações afetivas, seja na conjugalidade ou na parentalidade vivenciadas e experienciadas por gays, lésbicas e travestis, seja nas intersecções dessas questões com os meandros das lutas pelos direitos. O livro passa por um ponto nodal, tanto do ponto de vista teórico quanto da militância: as inúmeras possibilidades de construção de identidades.

A obra atravessa as concepções heteronormativas da sociedade ocidental, contrapondo-se sob diversas óticas aos binarismos e essencialismos no que diz respeito às formas de relacionamento "não-hegemônicas" que não sustentam a compreensão das dinâmicas da conjugalidade homoerótica/ afetiva, mas que, entretanto, são componentes que aparecem, por exemplo, nas relações de violência e manifestações de homofobia.

No eixo "Conjugalidades", o primeiro bloco de quatro textos, Antônio Crístian Saraiva Paiva, ${ }^{5}$ Adriana Nunan, ${ }^{6}$ Eduardo Saraiva ${ }^{7}$ e Rosangela de Barros Castro $^{8}$ tratam da conjugalidade homoerótica. A idéia que recorta os textos é, em parte, a colocação da conjugalidade em relação ao ideário de liberdade dos desejos de homens gays (dado no movimento LGBT) no século XX em contraposição à heteronormatividade, a valores como fidelidade, monogamia, relacionamentos fixos e duradouros, ou seja, ao enquadramento na norma heterossexual.

Os textos abordam a intimidade das relações conjugais (numa "micropolítica dos afetos"), a importância do relacionamento e da afetividade no "descobrir-se" homossexual e a opção por tornar visível a relação como temas complexos e permeados de dilemas que oscilam entre os "estereótipos" sobre a homossexualidade masculina e o igualitarismo e/ou hierarquização das relações homoafetivas.

A discussão sobre conjugalidades LGBT apresentada nos textos apresenta situações diversas e que são vistas de forma singular ao mesmo tempo que são tratadas como "fenômeno social típico das sociedades contemporâneas, resultado de uma luta política importante que vem sendo travada cotidianamente" (p. 10). A leitura desses artigos permite adentrar na intimidade das relações a tal ponto que nos faz pensar sobre uma conjugalidade plena, 9 mas que num certo sentido aponta para diferenciações no âmbito da conjugalidade homossexual. Em alguns casos, a idéia do "amor romântico" permanece, híbrida com a idéia de plenitude e fluidez das relações (como em Paiva e Saraiva); em outros as tensões entre a igualdade e a hierarquia aparecem pelos próprios preconceitos (internalizados ou não) que fragilizam as relações (Nunan), e também há casos em que a violência aparece como um constituinte da conjugalidade homossexual, hierarquizante (Castro). Mais do que pontos de vista analíticos diversos, é possível olhar nos textos possibilidades diversas da conjugalidade homossexual, que podem se dar por diversos fatores (classe, etnia/raça, geração, escolaridade, preferências), ainda que se trate aqui fundamentalmente de relações (homo)conjugais masculinas.

A questão das políticas e direitos homossexuais é tratada em cinco artigos, que encerram a primeira parte do livro, pelos/as autores/as Roger Raupp Rios, ${ }^{10}$ Rosa Maria Rodrigues de Oliveira, ${ }^{11}$ Miguel Vale de Almeida, ${ }^{12}$ Luiz Melo ${ }^{13}$ e por Anna Paula Uziel e Miriam Grossi. ${ }^{14}$ Intercruzando discursos do Direito sobre família e de especialistas diretamente ligados aos processos, trâmites e leis no Judiciário brasileiro, os textos de Rios e de Oliveira permitem pensar que o campo jurídico é fortemente influenciado por concepções tradicionais de família e casamento e pela "moral cristã" mesmo considerando-se laico. Em articulação com as constantes reflexões sobre o Judiciário que invisibiliza ainda a configuração de novas formas de família, especialmente as homoafetivas, Vale de Almeida, Mello e Uziel e Grossi discutem, respectivamente, as negociações nos campos políticos brasileiro, espanhol, português e francês no sentido de assegurar direitos civis LGBT. Esses 
direitos se referem principalmente à conjugalidade e parentalidade, pela inserção nos "formatos previstos pela legislação vigente", como é o caso do Brasil, ou "apontando a necessidade de uma redefinição legal que rompa com as categorias heterocentradas que estão nos princípios estruturadores da concepção hegemônica de família" (p. 13).

Vale de Almeida analisa o uso e os discursos políticos sobre o casamento de pessoas do mesmo sexo na Espanha. O Código Civil Espanhol (através da Lei n.13 de 3 de julho De 2005) garante igualdade plena de direitos para homossexuais para casamento e adoção e reconhecimento de filiação (Mello). Segundo Uziel e Grossi, o PaCs - Pacto Civil de Solidariedade - em vigor na França desde 1999 prevê uma série de direitos, mas não iguala as uniões hetero e homossexuais e nem concede o direito de adoção. Os artigos apontam as discussões e repercussões internas nos países onde tramitaram essas leis e que envolvem atores políticos, religiosos, militantes e intelectuais.

Algumas questões são postas para se pensar a busca pelos direitos: A legislação favorável às uniões e famílias homoafetivas impede a discriminação social? Reivindicar a regularização dessas uniões é entrar na (hetero)norma? Sem dúvida, as questões são muitas e foram fomentadas para ampliar um debate que aqui no Brasil deverá ainda ganhar novas amplitudes. Entretanto, é de fundamental importância a reflexão de como têm acontecido o debate e a regulamentação das uniões no exterior, como contraponto para as reflexões e proposições acerca de uma legislação no Brasil. Como afirmam as organizadoras e o organizador do livro, discutir a união homossexual é também apontar "[...] diferentes posições teóricas em torno da questão da conjugalidade, da família e da reprodução social" (p. 15). Os artigos fazem uma contribuição fundamental para que se possa compreender e legitimar esses "novos arranjos familiares".

Os artigos que compõem o eixo "Parentalidades" ou sobre as famílias homoparentais refletem questões do dia-a-dia familiar, dilemas e modos de vivenciar as relações "por meio dos olhares dos seus próprios protagonistas". Os quatro primeiros textos refletem os meandros das relações familiares, a parentalidade lésbica (Florência Herrera), ${ }^{15}$ as relações de travestis e suas famílias (Fernanda Cardozo), ${ }^{16}$ a parentalidade por homens homo/ bissexuais (André Geraldo Ribeiro Diniz e Claudia Andréa Mayorga Borges) ${ }^{17}$ e a busca pela "normalidade" em famílias homoparentais (Marcos R. V. Garcia, André G. Wolf, Eliane V. Oliveira, Janaina T. F. de Souza, Luana de O. Gonçalves e Mariana de Oliveira). ${ }^{18}$ O quinto aborda a homofobia entre mães heterossexuais acerca da homoparentalidade (Fernando S. Teixeira Filho, Lívia G. Toledo e Pedro H. Godinho) ${ }^{19}$ e os dois últimos artigos, de Elizabeth Zambrano ${ }^{20}$ e de Micaela Libson, ${ }^{21}$ discutem as representações sobre homoparentalidade na mídia, mais especificamente impressa, no Brasil e na Argentina.

As discussões sobre parentalidade de gays, lésbicas, travestis têm ganhado destaque e são um dos pontos nodais nas discussões e debates políticos e teóricos sobre direitos civis de gays, lésbicas e transgêneros. O conjunto dos artigos permite pensar os dois lados do debate. Entre os defensores de uma família heteronormativa, "a adoção de crianças por pessoas do mesmo sexo seria uma ameaça à sociedade e, no extremo, à própria espécie". Por sua vez, há inúmeros estudos e pesquisas que mostram "como crianças socializadas por casais de pessoas do mesmo sexo não são em praticamente nada diferentes daquelas socializadas por casais de pessoas de sexos diferentes" (p. 15), o que de maneira nenhuma faz com que tenhamos apenas dois pólos distintos na discussão; há uma infinita escala de cinzas entre esses pólos.

A questão das identidades perpassa todo o livro. Entretanto, na última parte da obra as identidades lésbicas são tratadas de maneira especifica em três artigos. Lenise Santana Borges $^{22}$ discute a (in)visibilidade e o modo como as relações lésbicas têm sido retratadas nas telenovelas da Rede Globo de televisão. ${ }^{23}$ Vanilda Maria de Oliveira ${ }^{24}$ discute "a intersecção identitária" nos significados atribuídos à lesbianidade entre a militância feminista negra de Goiânia. E Silvia Gomide ${ }^{25}$ debate a construção da identidade lésbica a partir de uma perspectiva queer, trazendo questões desestabilizadoras sobre as identidades lésbicas.

É neste liminar entre a desconstrução de concepções e normas hegemônicas de sexo, gênero e (homo)sexualidades e a prática cotidiana invisibilizada das relações entre atores sociais gays, lésbicas e transgêneros que as questões relativas a conjugalidades e parentalidades foram tecidas nesse livro numa variedade de abordagens teóricas e metodológicas, olhares diversos de muitas disciplinas e temáticas em diálogo profícuo. Essa obra, sem dúvida, é um marco e uma referência 
na produção sobre sexualidades e é fundamental para qualquer interessado/a nas temáticas sobre sexualidades, conjugalidades parentalidades, seja pesquisador/a, seja militante. É também uma ferramenta elucidativa para o debate político e social e para a discussão de adoção de novas políticas para atender o clamor por cidadania plena dos sujeitos envolvidos nessas novas possibilidades de relacionar-se.

\section{Notas}

' Em 2007 recebeu o prêmio de "Distinção em Publicações em Sexualidade" da SBRASH - Sociedade Brasileira de Estudos em Sexualidade Humana.

${ }^{2}$ Sobre afetividade e parentalidade homossexual ver também UZIEL, MELLO e GROSSI, 2006.

${ }^{3}$ Optei por usar LGBT (Lésbicas, Gays, Bissexuais e Transgêneros), pois é a primeira - mas não única designação que aparece no livro. Entretanto, há diversas siglas relacionadas à homossexualidade e/ou ao movimento homossexual organizado no Brasil. Ver Regina FACHINNI, 2005.

${ }^{4} \mathrm{~A}$ rede prevê pesquisas comparativas, encontros e publicações sobre as temáticas de conjugalidades de pessoas do mesmo sexo e parentalidade de pais e mães não heterossexuais.

5 "Reserva e invisibilidade: a construção da conjugalidade numa perspectiva micropolítica", p. 23-46.

6 "Influência do preconceito internalizado na conjugalidade homossexual masculina", p. 47-67.

7 "Encontros amorosos, desejos ressignificados: sobre a experiência do assumir-se gay na vida de homens casados e pais de família", p.69-88.

8 "Amor e ódio em relações 'conjugays'", p. 89-107.

${ }^{9}$ Anthony GIDDENS, 1993.

10 "Uniões homossexuais: adaptar-se ao Direito de Família ou transformá-lo? Por uma nova modalidade de comunidade familiar", p. 109-130.

11 "'Isto é contra a natureza...': acórdãos judiciais e entrevistas com magistrados sobre conjugalidades homoeróticas em quatro estados brasileiros", p. 131-152. 12 "O casamento entre pessoas do mesmo sexo. Sobre 'gentes remotas e estranhas' numa

'sociedade decente'", p. 153-168.

13 "Matrimônio entre pessoas do mesmo sexo na Espanha.
Do perigo social à plena cidadania, em quatro estações ", p. 169-168.

14 "Parceria civil e homoparentalidade: 0 debate francês", p. $189-210$

15 "La outra mamá: madres no biológicas em la pareja lésbica", p. 213-232.

16 "Performatividade de gênero, performatividade de parentesco: notas de um estudo com travestis e suas famílias na cidade de Florianópolis/SC", p. 233-252.

17 "Possíveis interlocuções entre parentesco e identidade sexual: Paternidade vivenciada por homens homo/ bissexuais", p. 253-276.

18 "'Não podemos falhar': A busca pela normalidade em famílias homoparentais", p. 277-300.

19 "A homofobia na representação da mães heterossexuais sobre a homoparentalidade", p. 301-320.

20 "Do privado ao público: a homoparentalidade na pauta do jornal Folha de São Paulo", p. 321-340.

${ }_{21}$ "Yo opino... Construciones discursivas sobre la homoparentalidad", p. 341-360.

22 “Lesbianidade na TV: visibilidade e 'apagamento' em telenovelas brasileiras", p. 363-384.

${ }^{23}$ Cabe lembrar o forte apelo que as novelas brasileiras têm no exterior.

24 “Identidades interseccionais e militâncias políticas", p. 385-404.

25 "Formação da identidade lésbica: do silêncio ao queer", p. $405-423$.

\section{Referências bibliográficas}

FACCHINI, Regina. Sopa de letrinhas? Movimento homossexual e produção de identidades coletivas nos anos 90 . Rio de Janeiro: Garamond, 2005.

GIDDENS, Anthony. A transformação da intimidade: sexualidade, amor e erotismo nas sociedades. 2. ed. São Paulo: Ed. da UNESP, 1993.

UZIEL, Anna Paula; MELLO, Luiz; GROSSI, Miriam (Orgs.). "Conjugalidades e parentalidades de gays, lésbicas e transgêneros no Brasil". Revista Estudos Feministas, v. 14, n. 2, 2006, p. 481-547. Dossiê.

Fátima Weiss de Jesus Universidade Federal de Santa Catarina 